\title{
Development and Evaluation of Stormwater Improvement Alternatives
}

\author{
Michael A. Gregory, John A. Aldrich, Michael F. Schmidt, Jeffrey E. \\ Duke, and Brian A. Barker
}

\begin{abstract}
After understanding and diagnosing urban stormwater management problems, the next important step is often prescribing improvement alternatives to address these problems. This chapter offers a practical discussion of design methodologies for developing stormwater improvement alternatives and for evaluating their hydraulic performance. An overview of alternative stormwater design options is given along with a discussion of alternative optimization and evaluation procedures. Case studies from projects in Ohio and Florida are used to highlight the approaches and methodologies presented.
\end{abstract}

\subsection{Introduction}

Stormwater management systems represent valuable public assets and provide many benefits to many users. By controlling floodwaters and preventing pollutants from reaching our rivers, lakes, and coastlines, stormwater management systems protect the health and safety of the public and the environment. In so doing, clean and healthy water resources support public drinking water supplies and can attract local investment through increased land values and tax revenue. Furthermore, they support water-based industries including recreational activities, tourism, commercial fishing, and basic manufacturing.

Despite massive investments in stormwater management systems and facilities, there will always be a need for capital improvement projects. Existing stormwater management systems may be inadequate for a variety of reasons, including:

Gregory, M., J. Aldrich, M.F. Schmidt, J.E. Duke and B. Barker. 2005. "Development and Evaluation of Stormwater Improvement Alternatives." Journal of Water Management Modeling R223-01. doi: 10.14796/JWMM.R223-01. (C) CHI 2005 www.chijournal.org ISSN: 2292-6062 (Formerly in Effective Modeling of Urban Water Systems. ISBN: 0-9736716-0-2) 
- $\quad$ structural deficiencies due to aging infrastructure that has exceeded its anticipated service life,

- growth and development resulting in changes to the amount and timing of runoff discharged into the system,

- changes in design criteria (e.g. relaxed design standards due to poor economic conditions, or increased design standards due to more stringent regulatory requirements),

- inadequate or improper management and planning,

- inadequate or improper maintenance and operation, and

- poor design or faulty construction.

Although the need for stormwater improvement projects will remain, the availability of public funds to implement these projects will vary. The funding gap for stormwater management programs and urban non-point source pollution control in the US has been estimated at $\$ 5.5$ billion and $\$ 4.4$ billion, respectively, based on needs reported by individual states as of January 2000 (US EPA, 2003). Less than half of the states submitted their reports, so the national need is larger.

It is expected that competing demands for limited public funds will continue, forcing engineers to develop prudent and cost-effective improvement projects to meet stormwater needs and user demands. The purpose of this chapter is to highlight issues and approaches in the development and evaluation of stormwater improvement alternatives and give examples using case studies.

\subsection{Evaluation of Stormwater Problems}

Stormwater problems represent an ongoing risk to public safety and property. Systems that are relatively problem-free today may pose risks under future land use conditions or due to alterations or failures of the existing system. This section summarizes and defines stormwater flooding problems and the methods for quantifying and prioritizing these problems.

\subsubsection{Problem Types}

Stormwater problem types include flooding, debris, erosion, and water quality. This chapter focuses on problems associated with flooding, particularly flooding related to the primary stormwater management system. The primary system represents the major drainage network elements that generally serve large tributary areas (greater than 10 acres, 4 ha). These systems include: 
- conveyance channels and conduits (e.g. rivers, streams, canals, ditches, culverts, pipes, streets, swales),

- storage facilities (e.g. lakes, ponds, detention/retention facilities, and street/yard surface depressions), and

- $\quad$ special control structures (e.g. gates, orifices, weirs, pumps).

The secondary stormwater system represents minor or local drainage network elements (e.g. inlets, collector pipes, ditches, swales, and small retention areas) that discharge into the primary system. These systems generally serve smaller areas (e.g. less than 10 acres or $4 \mathrm{ha}$ ) and are not addressed in this chapter.

Flooding is the inundation or overflowing of water onto land that is normally dry. Surface flooding can result from over-bank flooding of open channel systems or overflows from closed conduit systems. Submerged or inundated land surfaces may include both structures (e.g. roads and highways, railroads, residential and commercial buildings) as well as public and private property.

Stormwater flooding problems may be perceived differently by various users of the stormwater management system: what some consider minor nuisance flooding may be considered by others to be damaging. In either case, the perception is that the stormwater system does not provide its expected performance or level of service (LOS). Flooding thus becomes a problem when it is considered to be too severe and/or too frequent according to some set of accepted, watershed-specific LOS criteria. Typical LOS criteria used to evaluate flooding problems are described in detail elsewhere (Gregory et al., 2003).

From a stormwater master planning perspective, the inundation of floodwaters is generally considered to be a problem when damaging flooding results from deficiencies or failures of the primary stormwater management system and the flooding either:

- creates a public safety hazard,

- endangers public or private property, and/or

- disrupts the normal conduct of business.

In contrast, nuisance flooding is often due to deficiencies or failures within the secondary system, or in cases where the surface flooding does not present an immediate threat to structures or property. Examples of nuisance flooding and severe flood damage are shown in Figures 1.1 and 1.2.

\subsubsection{Problem Identification}

Stormwater flooding problems can be identified through observations in the field or as the result of hydrologic/hydraulic analysis and modeling. Field observations can be derived from: 


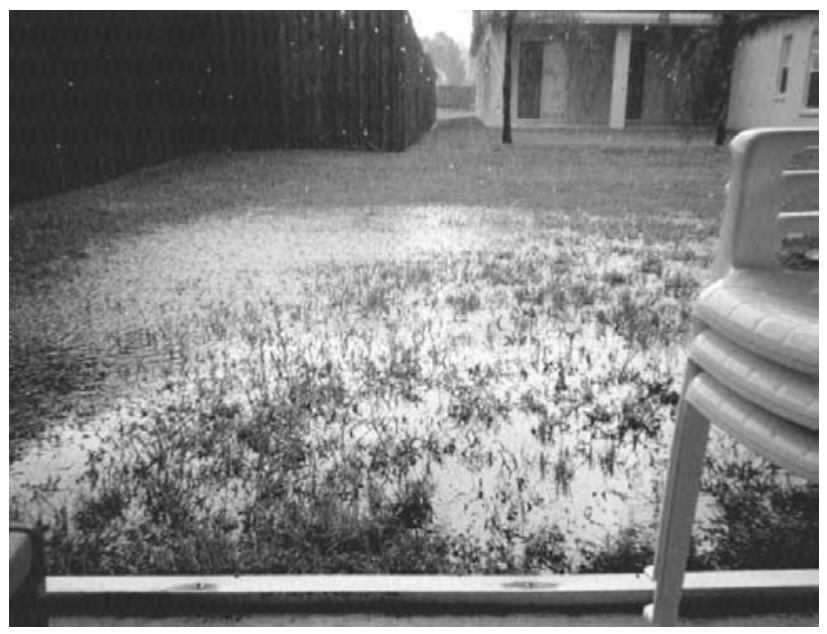

Figure 1.1 Nuisance flooding.

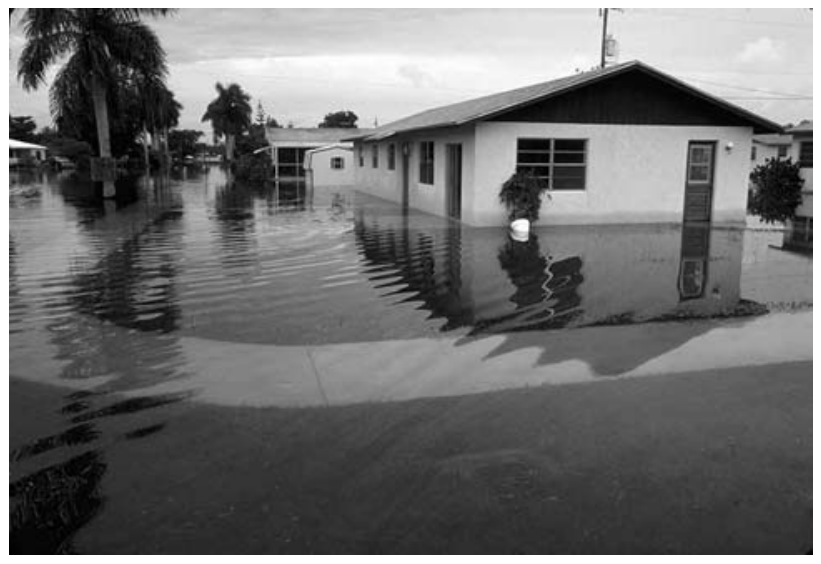

Figure 1.2 Severe flood damage.

- interviews with residents, local government, and agency staff,

- flooding complaint records,

- flow monitoring results,

- field reconnaissance surveys, and

- previous reports and studies.

Field observations alone often cannot pinpoint important cause-effect relationships in stormwater flooding. Modeling can be used to simulate the stormwater management system response for various conditions: 
- in locations where observations or measurements are not available,

- under rainfall conditions that have not yet been observed, but are likely to occur,

- under future land use conditions, and/or

- proposed management practices or system improvements.

Modeling that is not calibrated and validated against field observations may also have limited value. The limitation in this case is in the credibility of results, which can only be established by comparing computed results to observed behavior. The best way to diagnose stormwater problems is through the combination of field observations and hydrologic/hydraulic models.

\subsubsection{Problem Quantification}

Stormwater flooding problems can be quantified by the severity and frequency of flooding. The discharge rate alone is not sufficient to quantify damage potential or the LOS provided. Depth of flooding, and velocity, which imparts the momentum and energy of flow, are responsible for flood damage. Discussion in this chapter is limited to stage.

Flooding severity can be quantified in vertical, horizontal, and time dimensions. Table 1.1 shows typical characteristics of flood stage that can be used to quantify flooding severity. These characteristics are grouped by location and include building and roadway structures and private property. Flooding characteristics of other structures can be added, such as driveways and parking lots. Roadway flooding can be further categorized by defining a depth that is generally impassable by vehicular traffic (e.g. above 8 inches, $200 \mathrm{~mm}$ ). Also, residential building types can be differentiated between occupied dwelling units and other non-occupied structures such as garages.

Typically, it is the maximum depth of flooding that is specified in LOS criteria, which is represented by the peak flood stage in relation to the elevation of structure or property features. Likewise, inundation is also based on peak flood stage conditions and the areal extent of flooding can be measured by the area of inundation or by the number or length of inundated structures. The duration of flooding considers the range of flood stages above some specified threshold elevation.

Flooding frequency is typically characterized by the return period of the rainfall event that causes flooding. Rainfall events can include design storm events or historical storms with an assigned frequency. 
Table 1.1 Quantifying Flood Severity Based on Stage Characteristics.

\begin{tabular}{|c|c|c|c|}
\hline Location & Depth of Flooding & Area of Inundation & Duration of Flooding \\
\hline Buildings & $\begin{array}{l}\text { above finished floor } \\
\text { elevation } \\
\text { above basement } \\
\text { elevation }\end{array}$ & $\begin{array}{l}\text { \# flooded buildings } \\
\text { \# flooded basements }\end{array}$ & $\begin{array}{l}\text { above finished floor } \\
\text { elevation } \\
\text { above basement elevation }\end{array}$ \\
\hline Roadways & $\begin{array}{l}\text { road crown } \\
\text { in travel lanes } \\
\text { above manhole rim } \\
\text { above inlets }\end{array}$ & $\begin{array}{l}\text { length of inundated roadway } \\
\text { \# flooded intersections } \\
\text { \# flooded manholes } \\
\text { \# flooded inlets }\end{array}$ & $\begin{array}{l}\text { above road crown } \\
\text { in travel lanes } \\
\text { above manhole rim } \\
\text { above inlets }\end{array}$ \\
\hline Private & on property & property area inundated & on property \\
\hline Property & $\begin{array}{l}\text { above septic system } \\
\text { elevation } \\
\text { above streambank } \\
\text { elevation }\end{array}$ & $\begin{array}{l}\text { \# septic systems inundated } \\
\text { area of out-of-bank flooding }\end{array}$ & $\begin{array}{l}\text { above septic system } \\
\text { elevation } \\
\text { above streambank } \\
\text { elevation }\end{array}$ \\
\hline
\end{tabular}

\subsubsection{Problem Prioritization}

Even if funding were available, it is not feasible to solve every flooding problem, so stormwater flooding problems must be prioritized. Furthermore, individual problem locations are often grouped into discrete geographical planning units, or problem areas.

Flooding frequency is typically characterized by the return period of the Flooding problem locations in close proximity are often hydraulically dependent, particularly in flat or looped networks. Where problems are either interrelated or extensive in scope, the grouping of problem areas can help guide the development of improvement alternatives by identifying interrelationships between problems and solutions. Defining such planning units can help to focus improvements.

In order to prioritize problem areas, watershed-specific and sometimes neighborhood-specific ranking systems are often developed. Ranking systems typically include both objective scoring criteria related to observed or computed flooding characteristics combined with subjective weighting factors. Scoring criteria can be assigned to various flooding frequency and severity factors described earlier. Weighting factors need to be subjective in order to reflect the unique needs and desires of the public officials who manage the stormwater system and of the users who derive benefit from the system.

Table 1.2 shows a sample scoring system proposed for the Northeast Ohio Regional Sewer District (CDM et al., 2003). This system assigns a numeric 
score (up to a maximum of 10) for each problem type, based upon the severity of computed flooding problems:

- Building Flooding Score. For this study, the LOS criteria developed for existing buildings targeted a flood protection return period of $25 \mathrm{y}$. Base scores were assigned in cases where this LOS was not achieved, based on the number of buildings flooded within each defined problem area. Additional points were added for LOS deficiencies identified for storm events less than the desired return period (i.e. with a higher frequency of occurrence). Also, a score of 2 was added to critical buildings such as hospitals and fire stations.

- Interstate Highway and Railroad Flooding Score. The desired LOS criteria for existing Interstates and railroads were based on providing flood protection for a return period of $50 \mathrm{y}$. Base scores were assigned in cases where this LOS was not achieved, based on the depth and length of flooding.

- Arterial Roadway Flooding Score. The desired LOS criteria for existing arterial roadways were based on providing flood protection for a return period of $25 \mathrm{y}$. Base scores were assigned in cases where this LOS was not achieved, based on the depth and length of flooding within each defined problem area.

- Local Roadway Flooding Score. The desired LOS criteria for existing local roadways were based on providing flood protection for a return period of $10 \mathrm{y}$. Base scores were assigned in cases where this LOS was not achieved, based on the depth and length of flooding within each defined problem area.

Flooding depths greater than 8 inches $(200 \mathrm{~mm})$ were deemed "impassable" and assigned a higher base score. Likewise, roadway flooding exceeding 500 $\mathrm{ft}(150 \mathrm{~m})$ in length along the right-of-way was assigned a higher base score than shorter inundation lengths. Additional points were added for LOS deficiencies identified for storm events less than the desired return period.

The total score for each problem type was multiplied by a weighting factor to give an overall problem score. The problem types and corresponding weights developed for this study are shown at the bottom of Table 1.2. The team conducted several exercises with District staff to develop the weights based upon the relative importance compared with the other problem types. It was decided that, for this particular study, the highest importance should be assigned to building flooding protection which was assigned the highest weight. Using this scheme, building flooding was considered to be more than twice as important as arterial roadway flooding, five times as important as local street flooding, and ten times as important as a debris problem. 
Table 1.2 Sample flooding problem ranking system.

\begin{tabular}{|c|c|c|c|c|c|}
\hline \multicolumn{6}{|c|}{ Building Flooding score } \\
\hline \multirow[t]{2}{*}{ Number of Buildings } & \multicolumn{5}{|c|}{ Return Period } \\
\hline & $<50 \mathrm{y}$ & $<25 \mathrm{y}$ & $<10 \mathrm{y}$ & $<5 \mathrm{y}$ & $<2 \mathrm{y}$ \\
\hline $1-9$ & 0 & 2 & 3 & 4 & 5 \\
\hline $10-30$ & 0 & 4 & 5 & 6 & 7 \\
\hline$>30$ & 0 & 8 & 9 & 10 & 10 \\
\hline \multicolumn{6}{|c|}{ Interstate Highway and Railroad Flooding score } \\
\hline \multirow[t]{2}{*}{ Depth/L of Flooding } & \multicolumn{5}{|c|}{ Return Period } \\
\hline & $<50 \mathrm{y}$ & $<25 \mathrm{y}$ & $<10 \mathrm{y}$ & $<5 \mathrm{y}$ & $<2 \mathrm{y}$ \\
\hline Depth $<8$ ", L < $<500^{\prime}$ & 2 & 3 & 4 & 5 & 6 \\
\hline Depth $<8 "$, L $>500^{\prime}$ & 4 & 5 & 6 & 7 & 8 \\
\hline Depth $>8 "$, L $<500^{\prime}$ & 6 & 7 & 8 & 9 & 10 \\
\hline Depth $>8 "$, L > 500' & 8 & 9 & 10 & 10 & 10 \\
\hline \multicolumn{6}{|c|}{ Arterial Roadway Flooding score } \\
\hline \multirow[t]{2}{*}{ Depth/L of Flooding } & \multicolumn{5}{|c|}{ Return Period } \\
\hline & $<50 \mathrm{y}$ & $<25 \mathrm{y}$ & $<10 \mathrm{y}$ & $<5 \mathrm{y}$ & $<2 \mathrm{y}$ \\
\hline Depth $<8^{\prime \prime}, \mathrm{L}<500^{\prime}$ & 0 & 2 & 3 & 4 & 5 \\
\hline Depth $<8 "$, L $>500^{\prime}$ & 0 & 4 & 5 & 6 & 7 \\
\hline Depth $>8 "$, L $<500^{\prime}$ & 0 & 6 & 7 & 8 & 9 \\
\hline Depth $>8 ", \mathrm{~L}>500^{\prime}$ & 0 & 8 & 9 & 10 & 10 \\
\hline \multicolumn{6}{|c|}{ Local Roadway Flooding score } \\
\hline \multirow[t]{2}{*}{ Depth/L of Flooding } & \multicolumn{5}{|c|}{ Return Period } \\
\hline & $<50 \mathrm{y}$ & $<25 \mathrm{y}$ & $<10 \mathrm{y}$ & $<5 \mathrm{y}$ & $<2 \mathrm{y}$ \\
\hline Depth $<8^{\prime \prime}, \mathrm{L}<500^{\prime}$ & 0 & 0 & 2 & 3 & 4 \\
\hline Depth $<8^{\prime \prime}, \mathrm{L}>500^{\prime}$ & 0 & 0 & 4 & 5 & 6 \\
\hline Depth $>8$ " $^{\prime \prime}, \mathrm{L}<500^{\prime}$ & 0 & 0 & 6 & 7 & 8 \\
\hline Depth $>8 "$, L > $>500^{\prime}$ & 0 & 0 & 8 & 9 & 10 \\
\hline \multicolumn{6}{|c|}{ Weighting Factors } \\
\hline \multicolumn{5}{|c|}{ Type of Problem } & $\mathrm{Wt}$ \\
\hline & & & Buil & Flooding & 5 \\
\hline \multirow{2}{*}{\multicolumn{5}{|c|}{$\begin{array}{r}\text { Interstate Highway, Arterial Roadway, and Railroad } \\
\text { Flooding } \\
\text { Streambank Erosion }\end{array}$}} & 2 \\
\hline & & & & & 1.5 \\
\hline \multicolumn{5}{|c|}{ Local Roadway Flooding } & 1 \\
\hline & & & & Debris & 0.5 \\
\hline
\end{tabular}


Table 1.3 shows flooding results at one problem area that featured building and local roadway flooding. The base building flooding score was 4 , since 10 to 30 buildings were flooded at the desired 25 y LOS return period. An additional 2 points were added to the score for the $5 \mathrm{y}$ building flooding occurrences, resulting in total building flooding score of 6 .

Similarly, the base roadway flooding score was 8 , since the roads were impassable and the total length of flooding exceeded $500 \mathrm{ft}(150 \mathrm{~m})$ for the desired 10 y LOS return period. An additional point was added for the roadway flooding at a $5 \mathrm{y}$ return period, resulting in total local roadway flooding score of 9 . By applying the appropriate weighting factors, the total flooding severity score for this problem location was 39 (i.e. $6 \times 5+9 \times 1$ ).

Table 1.3 Example flooding results.

\begin{tabular}{|c|c|c|c|c|}
\hline \multicolumn{5}{|c|}{ Building Flooding Occurrences (Number of Buildings) } \\
\hline$<50 \mathrm{y}$ & $<25 \mathrm{y}$ & $<10 \mathrm{y}$ & $<5 \mathrm{y}$ & $<2 \mathrm{y}$ \\
\hline 45 & 28 & 12 & 5 & 0 \\
\hline \multicolumn{5}{|c|}{ Local Roadway Flooding Occurrences (Max. Depth, Length of Flooding } \\
\hline$<50 \mathrm{y}$ & $<25 \mathrm{y}$ & $<10 \mathrm{y}$ & $<5 \mathrm{y}$ & $<2 \mathrm{y}$ \\
\hline $1.5 \mathrm{ft}, 2200 \mathrm{ft}$ & $1.1 \mathrm{ft}, 1300 \mathrm{ft}$ & $0.9 \mathrm{ft}, 900 \mathrm{ft}$ & $0.3 \mathrm{ft}, 200 \mathrm{ft}$ & $0 \mathrm{ft}, 0 \mathrm{ft}$ \\
\hline
\end{tabular}

\subsection{Stormwater Improvement Alternatives}

The development of stormwater improvement alternatives can proceed once priority problem areas have been defined. In small watersheds where site constraints and opportunities are well defined, developing the appropriate improvements may be relatively straightforward. In large watersheds where site constraints and opportunities are poorly defined or unknown, and many permutations of alternatives can be developed, appropriate improvements can be difficult to determine. This section presents a general strategy for developing improvement alternatives and summarizes the various solution types and general design options available.

\subsubsection{Conceptual Design Strategy}

A strategy is needed in order to develop solutions, and should be developed during the conceptual design phase (i.e. before the preliminary design phase), based on the unique constraints and opportunities offered by the watershed. These are often initially identified during the problem identification 
interviews with residents and public officials, and refined as the project proceeds.

Table 1.4 FEMA floodplain management strategies and solutions.

\begin{tabular}{cl}
\hline Strategy & \\
\hline Modify & Floodplain regulations \\
Susceptibility to & Land use planning codes and ordinances \\
Flood Damage & Engineering design policies and standards \\
& Floodplain preservation and restoration \\
& Floodproofing flood-prone structures \\
& Flood forecasting/warning systems \\
Modify Impact of & Public information and education programs \\
Flooding & Emergency response plans \\
& Disaster assistance, flood insurance and financial incentives \\
& Post-flood recovery plans \\
Modify Flooding & Facilities to store excess runoff \\
& Dikes, levees, and floodwalls to keep excess runoff away \\
& Channel improvements to convey excess runoff \\
& Runoff source controls that encourage infiltration and on-site detention \\
Preserve and & Regulations to protect environmentally sensitive areas \\
Restore Natural & Land use planning codes and ordinances \\
& Engineering design policies and standards \\
& Floodplain, open space, and wetland preservation and restoration \\
& Public information and education programs \\
& Financial incentives \\
\cline { 2 - 3 } &
\end{tabular}

The types of improvement alternatives are subject to numerous constraints that are highly site-specific, but generally fall into one of the following categories:

- Technical. Design constraints may include unfavorable hydraulic, geologic, or geographic conditions, presence of conflicting utilities, environmentally sensitive areas, hazardous sites, permitting challenges, etc.

- Financial. This includes both funding constraints on implementing the improvement program as well as economic concerns that may affect the costs of certain materials or technologies that would influence the selection of improvement alternatives. 
- Political. These constraints are often harder to identify but include socio-political influences that affect institutional and regulatory policies.

On the other hand, unique and site-specific opportunities may exist within a watershed to help refine the selection of stormwater improvements. These may include such items as:

- available or unused conveyance/storage capacity,

- available public land, parks, corridors, etc.,

- coordination with other transportation, utility improvement, or redevelopment projects,

- opportunities to provide multi-purpose facilities,

- new funding mechanisms such as grants, loans, bonds, dedicated stormwater utility, etc.,

- new materials and technologies, and

- educational opportunities to enhance public and political support, to refine current constraints and to refine funding, institutional, or regulatory issues.

A meaningful design strategy needs performance standards or targets with which to measure and evaluate hydraulic benefits. The LOS criteria used to prioritize problem areas embody the local government drainage goals, objectives, and standards in a stormwater management context (Gregory et al., 2003). These criteria also provide an objective basis for developing and evaluating improvement alternatives. Depending on the problems and funding constraints, it may be necessary to refine the prioritization LOS criteria in order to develop improvement alternatives.

\subsubsection{Stormwater Solution Types}

There are many types of non-structural and structural measures that can either solve or alleviate stormwater flooding problems. The US Federal Emergency Management Agency (FEMA) has adopted four main floodplain management strategies (French and Associates Ltd., 1998). Table 1.4 summarizes the nonstructural and structural measures that can be used to achieve these strategies, which include:

- modify human susceptibility to flood damage by reducing disruption through avoidance of hazardous, uneconomic or unwise use of floodplains,

- modify the impact of flooding by assisting individuals and communities prepare for, respond to and recover from flood damage, 
- modify flooding itself by constructing improvements that control floodwater, and

- $\quad$ preserve and restore natural resources by reestablishing and maintaining floodplain environments in their natural state.

These solution types can be adapted and applied in a broader stormwater management context. The focus of this chapter is on structural solutions and these are described in the following section.

\subsubsection{Structural Improvement Types}

Runoff source controls limit the discharge of runoff into the stormwater management system. Runoff can be controlled at its source by:

- reducing the amount of impervious cover through alternative site development designs that reduce the area of pavement and concrete on roadways, parking lots, and sidewalks, or through the use of pervious paving materials, and

- constructing stormwater management facilities that promote infiltration of runoff into the soil.

Investments in runoff source controls will minimize the cost of all the other types of structural improvements that merely redistribute stormwater runoff within the system. Apart from source controls, there are three ways to control excess runoff in stormwater management systems:

- Convey excess runoff elsewhere. This involves moving flows to an appropriate location either by gravity or pumping. Conveyance improvements are discussed below.

- Store excess runoff. This involves detention or retention to hold back flows at critical times. Detention improvements are discussed below.

- Accommodate excess runoff. This involves either preventing or minimizing damage to flood-prone structures. Floodplain management improvements are discussed below.

Conveyance Improvements: Conveyance improvements are often the best hydraulic solution to flooding problems that are caused by a localized constriction. These improvements are typically designed to increase conveyance capacity, allowing the water to move more quickly or efficiently downstream away from the flooded area. While generally improving flooding conditions upstream, an evaluation of conveyance improvements must consider the potential increase of flooding conditions downstream. Table 1.5 shows various conveyance improvement options.

Detention Improvements: Detention improvements are often the best hydraulic solution to flooding problems caused by excessive runoff volume or where conveyance improvements are ineffective. While detention generally 
improves flooding conditions downstream, an evaluation of storage improvements must consider increases in flooding conditions upstream, particularly in areas of flat terrain. Detention facilities can also be extended to include design features that promote the settling of pollutants captured by the facility and reduce erosive flow velocities downstream of the facility. Table 1.6 shows various detention improvement options.

Floodplain Management Improvements: Floodplain management improvements address flooding problems by either preventing flooding, or by keeping excess runoff away from buildings or roadways. Decisions to use floodplain management improvements are usually based on cost rather than hydraulic benefit, i.e. in cases where the costs of conveyance and detention options are high compared to their effectiveness. Buy-out is included here as a structural solution, since heavy equipment is typically used to demolish the structure and to re-grade the land after purchase. The raising of roads should be considered as a last resort option. Minor resurfacing projects might be beneficial, but extensive road raising will reduce available surface storage and could result in new flooding problems elsewhere. Table 1.7 shows various floodplain management improvement options.

\subsubsection{Measures Preserving Existing System Capacity}

The recommended structural solutions to drainage problems will only achieve the desired level of flood control if appropriate measures are implemented to maintain the capacity of the existing primary stormwater management system. These measures include:

- Ongoing maintenance program. This program could include routine and as-needed maintenance activities to remove vegetation, silt, sediment, and debris from the system in order to achieve its original design capacity. Maintenance alone may solve current flooding problems. Figure 1.3 shows an example of excessive debris that exacerbates upstream flooding problems.

- Repair and replacement program. An annual investment in renewing aging stormwater infrastructure helps to preserve the structural integrity of the system and may extend its useful life, prevent failures, and assure reliable service.

- Floodplain preservation. Preserving existing floodplains helps to retain natural flood storage volumes, allows natural stream morphologic processes to occur, and protects stream and riparian habitat. This can be achieved through ordinance modifications that prohibit floodway encroachment or floodplain fill, easement acquisition, or establishing setbacks. Preservation of floodplain storage can also be tied to various land use planning initiatives, 
which can significantly reduce the capital cost of recommended structural improvements.

- Runoff source controls for future development. On-site detention/retention and runoff volume controls are recommended to limit future flooding, erosion, and water quality problems in developing areas. These can be achieved through ordinance modifications and regulatory compliance with costs typically borne by the property developer.

\subsubsection{Modeling Considerations}

After calibration, model parameters are often adjusted to model the effectiveness of improvements in meeting the desired design LOS criteria. For the hydrologic model, this typically involves using the appropriate design storm event(s), soil moisture conditions, and/or groundwater assumptions. Also, the boundary and initial conditions represented in the hydraulic model must be appropriate for the selected design storm event(s).

Furthermore, future growth and management strategies must be represented in the model parameters. The typical design life of stormwater improvements is on the order of 10-25 y or more (i.e. commensurate with the frequency implied by the design LOS criteria). As a result, assumptions must be made concerning how the stormwater management system will be maintained and how land use and development changes will affect runoff over the appropriate planning horizon. For the hydrologic model, this may include build-out land use assumptions based on future land use zoning plans, or on redevelopment and infill opportunities. Generally these land use planning assumptions are conservative in terms of runoff potential. For the hydraulic model, this may include maintenance, repair and replacement programs, and the addition of planned capital improvement projects.

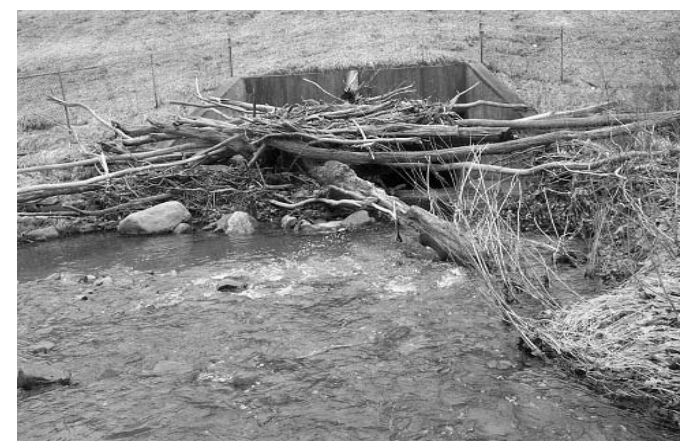

Figure 1.3 Debris clogging an inlet. 
Table 1.5 Conveyance improvement options.

\begin{tabular}{ll}
\hline \multicolumn{1}{c}{ Type } & \multicolumn{1}{c}{ Description } \\
\hline Bridge replacement & Replacement of existing bridge \\
Culvert replacement & Replacement of existing culvert \\
Culvert addition & Addition of culvert, parallel to existing culvert \\
Constrained channel & Channel widening/regrading to increase flow capacity, \\
improvements & constrained by available space \\
Unconstrained channel & Available space allows room to construct two-stage \\
improvements & naturalized stream \\
Channel realignment & New channel alignment within the same reach \\
Diversion channel & Diversion channel to a new reach, tributary, or watershed \\
Storm sewer replacement & Replacement of existing storm sewer pipe \\
Storm sewer addition & Addition of storm sewer pipe, parallel to existing storm \\
sewer & New storm sewer alignment within the same reach \\
Storm sewer realignment & Diversion storm sewer to a new reach, tributary, or \\
Diversion storm sewer & watershed \\
New pump station & $\begin{array}{l}\text { Construct a new pump station where gravity solutions are } \\
\text { not feasible }\end{array}$ \\
Modify existing pump station (upgrade capacity or \\
reconfiguration of operating controls)
\end{tabular}

Table 1.6 Detention improvement options.

\begin{tabular}{ll}
\hline \multicolumn{1}{c}{ Type } & \multicolumn{1}{c}{ Description } \\
\hline $\begin{array}{l}\text { Modify existing detention } \\
\text { facility }\end{array}$ & $\begin{array}{l}\text { Provide additional storage and/or reconfiguration of control } \\
\text { structures } \\
\text { Open detention facility } \\
\text { Construct a new detention facility, generally using open } \\
\text { excavation }\end{array}$ \\
Detention facility with closed top, generally underground \\
Closed detention facility & $\begin{array}{l}\text { In-line dam/control structure within open channel to impound } \\
\text { wavine storage/Stream }\end{array}$ \\
impoundment & $\begin{array}{l}\text { Regulate inlets to allow storage within street right-of-way or } \\
\text { parking lot } \\
\text { Street/Parking lot storage } \\
\text { Dredging of deposited sediment, etc from lakes, ponds, } \\
\text { streams, or channels } \\
\text { Capacity restriction within existing pipe (e.g. orifice plate to } \\
\text { throttle flows) }\end{array}$ \\
\hline
\end{tabular}


Development of alternative solutions involves the sizing of candidate improvements to achieve the desired performance goals, as quantified by the LOS criteria discussed above. The selection of specific improvement options requires an understanding of the nature of flooding problems, a sense of how the stormwater management system responds under different hydrologic and hydraulic conditions, as well as knowledge of the local site constraints and opportunities as discussed earlier.

The general process of developing alternative improvements involves:

1. choosing a logical set of improvement options from above,

2. making initial sizing estimates, and

3. refining the size and configuration of improvements until model results indicate the desired design LOS criteria are achieved.

\subsection{Evaluation of Improvement Alternatives}

When a number of alternatives have been developed, an evaluation of costs and benefits must be performed to identify and recommend a preferred alternative. This section discusses issues in the optimization and evaluation of improvement alternatives.

\subsubsection{Alternative Optimization}

Even when a set of improvements meets the desired design LOS criteria, there are still some considerations that may affect their size and configuration.

\section{Cumulative Impacts}

Improvements developed to solve problems at one location may increase flooding or cause new flooding problems in other areas. As a result, the impact of improvements needs to be evaluated across the entire system, and not just focused on the problem areas.

Conveyance improvements generally increase stages and velocities downstream. Although storage improvements are often designed to reduce stages and velocities downstream, the timing of the peak discharge may coincide with the peak system response at a location downstream resulting in increased stages (Cunningham and Schmidt, 1993).

An evaluation of the cumulative impacts of proposed improvements could be used to identify occurrences where:

- peak flood stage or velocity have increased compared to baseline conditions,

- LOS criteria used to identify problems have been exceeded, or 
- design LOS criteria have been exceeded.

Design decisions on how to address these new flooding occurrences depend on the specific project goals and objectives.

\section{Multi-Objective Design}

Design LOS criteria for the structural solutions described earlier typically involve rare storm events (e.g. with a return period of $10 \mathrm{y}$ or more). Some improvements can be modified to perform additional functions for the more frequent events, during which water quality or stream bank erosion problems are critical issues.

Multi-objective designs depend to a large extent on the unique site constraints and opportunities mentioned earlier. Examples of multi-objective conveyance improvements include the "naturalization" of open channels to accommodate or minimize stream bank erosion. Examples of multi-objective detention improvements include water quality treatment or control features.

\section{Design LOS Criteria Adjustments}

Another consideration when evaluating improvement alternatives is the adjustment of design LOS criteria. Often, one must wait until a number of alternatives have been developed in order to better understand the need to make such adjustments. There may also exist unsolvable flooding problems in which no feasible solution exists for the stated LOS criteria or where implementation costs are obviously prohibitive. In such cases, it may be advisable to reduce the design LOS criteria in order to develop more costeffective alternatives.

\subsubsection{Alternative Evaluation Criteria}

Alternatives evaluation is more than just identifying the set of improvements that achieves a specified level of hydraulic performance. In determining the optimal set of collection system or facility improvements to address a flooding problem, several factors must be considered.

The range of benefits derived from the improvements represents the range of user expectations. The range of improvement costs will vary between how much users are willing to pay and how much they can afford. An evaluation of improvement benefits and costs can help to distinguish the optimal set of alternatives in terms of highest benefit to cost ratio. At the conceptual design stage, a cost-benefit analysis does not always identify the clearly superior alternative, given the higher uncertainty in cost assumptions. In such cases however, a cost-benefit analysis is essential for eliminating any potential high-cost, low-benefit alternatives. 
Similar to the problem prioritization discussed earlier, watershed-specific ranking systems are often developed to evaluate improvement alternatives. Objective scoring criteria are related to the benefits and costs of improvements. Subjective weighting factors are used to determine the relative importance of individual benefit and cost factors, which are necessarily related to the project goals.

\section{Benefit Considerations}

In addition to the hydraulic performance that can be objectively measured by design LOS criteria, there are other important benefits that can be derived from improvement alternatives, including:

- Compatibility with public interests. Acceptance of proposed improvements by the public and elected officials is a critical factor in the successful implementation of a capital improvement program. Alternatives that support community interests should be preferred over those that do not. Community interests cover a range of social and political factors that may be highly variable between communities. Examples of preferable improvement alternatives include those that offer multi-use opportunities, such as park facilities, development of waterfront properties, bike trails, and walking paths. In such cases, capital improvement programs are often coordinated with local land use planning initiatives.

- Compatibility with regulatory requirements. Collection systems, open watercourses and water bodies are subject to numerous regulatory requirements. Alternatives that meet these requirements should be preferred over those that do not. Regulatory requirements include those administered by the US EPA (e.g. Total Maximum Daily Load (TMDL) and National Pollutant Discharge Elimination System (NPDES) programs), by FEMA (e.g. National Flood Insurance Program), and by individual state agencies (e.g. dam safety requirements, which regulate the construction and maintenance of dams and water body impoundments to protect against potential catastrophic failure).

- Enhancements to water quality and/or natural habitat. Water quality benefits can be derived from improvements that help to reduce the loading or concentration of pollutants within the stormwater management system. Benefits to the natural habitat can also be achieved from improvements that restore stream or riparian habitats. Alternatives that include these beneficial features should be preferred over those that do not. Furthermore, 
alternatives that feature water quality or habitat enhancements may qualify for additional local, state, or federal funding.

- Implementation issues. Improvement alternatives that are easier to build are generally preferred over those that present construction challenges. Implementation indicators that may be considered include site access and equipment staging considerations, public disruption, utility conflicts, easement requirements, relative operation and maintenance requirements, and many other design and permitting details.

\section{Cost Considerations}

The cost of improvement alternatives developed during the conceptual design phase may include estimates of the capital costs associated with design, permitting, construction and administration, as well as costs related to the acquisition of property, right-of-way, and easements.

It is also useful to include a consideration of costs over the full design lifecycle of proposed improvements, which includes items related to the operation and maintenance of new facilities. A common assumption is that there would be no additional operation and maintenance costs required for existing facility enhancements and replacements. An appropriate planning horizon should be used when converting annual operation and maintenance costs into total present worth. The overall program cost can then be estimated by combining capital and operational costs.

Additional cost considerations can include negative benefits identified for proposed improvement alternatives. These items are often difficult to quantify at the conceptual design phase, but could include:

- undesirable community impacts that are incompatible with public interests, which may include improvements that result in extensive easement or property acquisitions, disruption to business or relocations, or conflict with other local government plans and policies;

- safety and aesthetic concerns due to proposed structures, facilities, or impoundment of water;

- negative environmental impacts such as those that present regulatory challenges and/or require mitigation measures; and

- implementation challenges, such as those that present construction risks and uncertainties. 


\subsection{Case Studies}

Two case studies are presented that feature different approaches to the alternatives evaluation:

- Case Study 1 represents a relatively small watershed where solutions were generally known in advance, since site constraints and opportunities were well documented. As a result, the structural improvement types were fixed, but the design LOS criteria were varied between alternatives.

- Case Study 2 represents a large regional watershed planning study where structural improvement types were varied, but the design LOS criteria were fixed between alternatives.

\subsubsection{Case Study 1: Clearwater, Florida}

For the Myrtle Avenue Stormwater Improvement Project, Phase 1, conceptual stormwater collection system improvements along Myrtle Avenue were designed to meet the City of Clearwater stormwater LOS standards for road flooding (CDM Inc., 2001).

The key goals of the study were:

- development of a conceptual plan for developing a reliable, cost-effective solution to modify the existing storm sewer system to address chronic flooding problems along Myrtle Avenue, and

- application of appropriate level of service standards, balancing flooding risks with available funding for construction and maintenance of improvement alternatives.

The contributing watershed area is 0.8 square miles $\left(2.1 \mathrm{~km}^{2}\right)$ and drains the central business district of downtown Clearwater, as shown in Figure 1.4. The storm sewer system includes 7.5 miles $(12 \mathrm{~km})$ of pipes, a 4 acre (1.6 ha) stormwater quality treatment lake and park amenity, and four major outfalls that discharge into Clearwater Harbor in the Gulf of Mexico. The system was modeled using EPA SWMM and included a representation of the surface overflow system to more accurately predict street and building flooding (Huber and Dickinson, 1988). The reliability of the model was improved by calibrating the model to match flow measurements using continuous simulation and by validating the model to match observed high water marks throughout the watershed for a rare storm event ( $25 \mathrm{y}$ return period). 
Table 1.7 Floodplain management improvement options.

\begin{tabular}{|c|c|}
\hline Type & Description \\
\hline Buy-out & Purchase and demolition of home, business, and/or private property \\
\hline Relocate & Relocation of residential building \\
\hline Flood berm & Dykes or berms using earthen materials \\
\hline Flood wall & Flood walls, dykes, or levees using concrete material or sheet piling \\
\hline Floodproofing & Closures and sealants to waterproof existing buildings \\
\hline $\begin{array}{l}\text { Flood warning } \\
\text { systems }\end{array}$ & $\begin{array}{l}\text { Real-time monitoring, detection and notification of hazardous } \\
\text { conditions }\end{array}$ \\
\hline House raising & Elevate supporting structure of house \\
\hline Road raising & $\begin{array}{l}\text { Additional pavement/base material layers to eliminate minor road } \\
\text { flooding }\end{array}$ \\
\hline
\end{tabular}

Summary of Alternatives

Three alternatives were developed for various levels of flood protection. For each alternative, the flooding severity described by the LOS criteria was constant, allowing a maximum road flooding depth of $0.25 \mathrm{ft}(75 \mathrm{~mm})$ over the road crown, but the flooding frequency varied. The alternatives that were developed included:

1. $12,160 \mathrm{ft}(3710 \mathrm{~m})$ pipe improvements sized to achieve the design LOS criteria for the $25 \mathrm{y} / 24 \mathrm{~h}$ design storm. This return period was consistent with the City's design standards for road flooding protection for new development.

2. $6,115 \mathrm{ft}(1860 \mathrm{~m})$ pipe improvements sized to achieve design LOS criteria for the $5 \mathrm{y} / 24 \mathrm{~h}$ design storm event, the minimum expected LOS.

3. $7,080 \mathrm{ft}(2160 \mathrm{~m})$ pipe improvements sized to achieve design LOS criteria for the $10 \mathrm{y} / 24 \mathrm{~h}$ design storm event, selected to lie within the range defined by Alternatives 1 and 2 .

Structural improvement types included:

- Conveyance improvements. Proposed pipe sizes were varied to meet the specified design LOS criteria. Each alternative included common detention improvements representing the Town Lake Rehabilitation Project, located in the eastern portion of the study area. 
Table 1.8 Case Study 1 - Summary of road and building flooding.

\begin{tabular}{lrrrrrr}
\hline \multirow{2}{*}{$\begin{array}{c}\text { Proposed } \\
\text { Improvement }\end{array}$} & \multicolumn{2}{c}{$5 \mathrm{y} / 24 \mathrm{~h}$ Event } & \multicolumn{2}{c}{$10 \mathrm{y} / 24 \mathrm{~h}$ Event } & \multicolumn{2}{c}{$25 \mathrm{y} / 24 \mathrm{~h}$ Event } \\
\cline { 2 - 7 } & $\begin{array}{r}\text { Road } \\
\text { Flooding }\end{array}$ & $\begin{array}{r}\text { Building } \\
\text { Flooding }\end{array}$ & $\begin{array}{r}\text { Road } \\
\text { Flooding }\end{array}$ & $\begin{array}{r}\text { Building } \\
\text { Flooding }\end{array}$ & $\begin{array}{r}\text { Road } \\
\text { Flooding }\end{array}$ & $\begin{array}{r}\text { Building } \\
\text { Flooding }\end{array}$ \\
\hline $\begin{array}{l}\text { Existing } \\
\text { System }\end{array}$ & 30 & 7 & 38 & 20 & 51 & 25 \\
$\begin{array}{l}\text { Alternative 2 } \\
(5 \text { y) }\end{array}$ & 6 & 0 & 21 & 0 & 42 & 4 \\
$\begin{array}{l}\text { Alternative } 3 \\
(10 \text { y) }\end{array}$ & 5 & 0 & 12 & 0 & 33 & 2 \\
$\begin{array}{l}\text { Alternative } 1 \\
(25 \text { y) }\end{array}$ & 5 & 0 & 7 & 0 & 15 & 1 \\
\hline
\end{tabular}

\section{Alternatives Evaluation}

Table 1.8 summarizes the road and building flooding locations within the study area. Alternatives are ranked in increasing order of return period and compared to existing system LOS deficiencies (i.e. locations where the design LOS criteria were not met). There were a few locations where hydraulic benefits were limited and therefore the design LOS criteria could not be achieved by proposed alternatives. For example, Alternative 2 improvements were sized to provide a maximum road flooding depth of $0.25 \mathrm{ft}(75 \mathrm{~mm})$ for the $5 \mathrm{y}$ design storm event, but this level of flood protection could not be achieved at 6 locations. Similarly a 10 y LOS could not be achieved at 12 locations by Alternative 3 improvements and a 25 y LOS could not be achieved at 15 locations by Alternative 1 improvements. Building flooding LOS deficiencies are indicated by the number of potentially inundated buildings for the corresponding design storm event. Only those buildings that met the City's building code criteria of a minimum first floor elevation at least $1 \mathrm{ft}(300 \mathrm{~mm})$ above the road centerline elevation were included.

Alternatives were evaluated by comparing the relative benefit (measured in terms of reduced road and building flooding LOS deficiencies) versus the construction cost of stormwater improvements. The capital cost of stormwater improvements was estimated for each alternative:

- Alternative $2(5$ y LOS $)=$ USD $\$ 3.3$ million,

- Alternative $3(10$ y LOS $)=$ USD $\$ 4.5$ million, and

- Alternative $1(25$ y LOS $)=$ USD\$6.9 million.

The reduction in LOS deficiencies was based on comparing the resulting number of road or building flooding deficiencies for each alternative with the number of deficiencies in the existing system. For example, for the $5 \mathrm{y} / 24 \mathrm{~h}$ storm event, there were 30 road and 7 building flooding LOS deficiencies indicated for the existing system, and 6 road and 0 building flooding LOS deficiencies for Alternative 2. Therefore, Alternative 2 eliminated 24 road and 
7 building flooding deficiencies. Dividing these numbers into the construction cost gives the cost per reduction in LOS deficiencies. For example, for the 5 $\mathrm{y} / 24 \mathrm{~h}$ storm event, Alternative 2 eliminates 24 road and 7 building flooding deficiencies, which is equivalent to $\$ 136,545$ per road flooding deficiency eliminated and $\$ 468,154$ per building flooding deficiency eliminated.

These cost-benefit ratios were calculated for five design storm events (i.e. the 2-, 5-, 10-, 25-, and $100 \mathrm{y} / 24 \mathrm{~h}$ storms) and plotted as shown in Figure 1.5 and Figure 1.6. The number of LOS deficiencies eliminated by each alternative is plotted on the horizontal axis and the cost per LOS deficiency eliminated is plotted on the vertical axis.

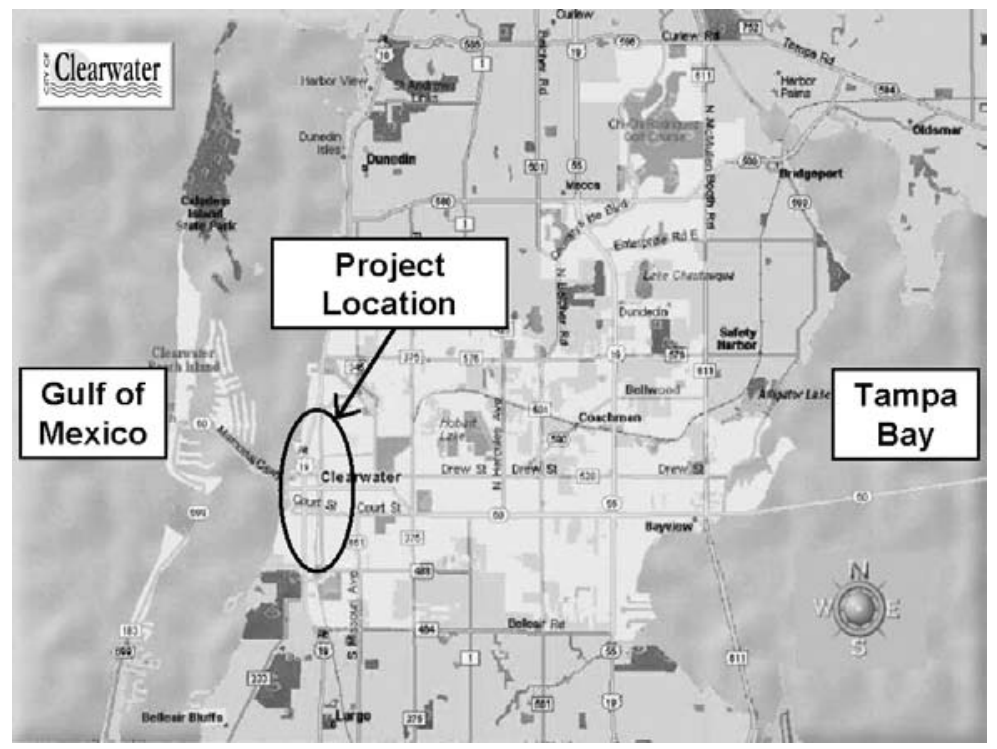

Figure 1.4 Case Study 1 project location (Clearwater Florida).

Although Alternative 1 ( 25 y LOS) provides the maximum benefits by eliminating the most LOS deficiencies, the lowest cost per deficiency eliminated is indicated by Alternative 2 ( 5 y LOS) for both road and building flooding. Therefore, Alternative 2 provides the best cost/benefit ratio in terms of cost per LOS deficiency and was recommended over Alternatives 1 and 3.

\subsubsection{Case Study 2: Cleveland, Ohio}

For the Northeast Ohio Regional Sewer District's Regional Intercommunity Drainage Evaluation (RIDE) study, planning-level solutions were developed to alleviate intercommunity drainage problems for a large, multi-jurisdictional 
drainage area within the greater Cleveland metropolitan area (CDM Inc. et al., 2003).

The key goals of the study were:

- development of planning-level solutions and costs for alleviation of intercommunity drainage problems that presented an immediate threat of flooding or stream bank erosion to structures, roadways, and infrastructure,

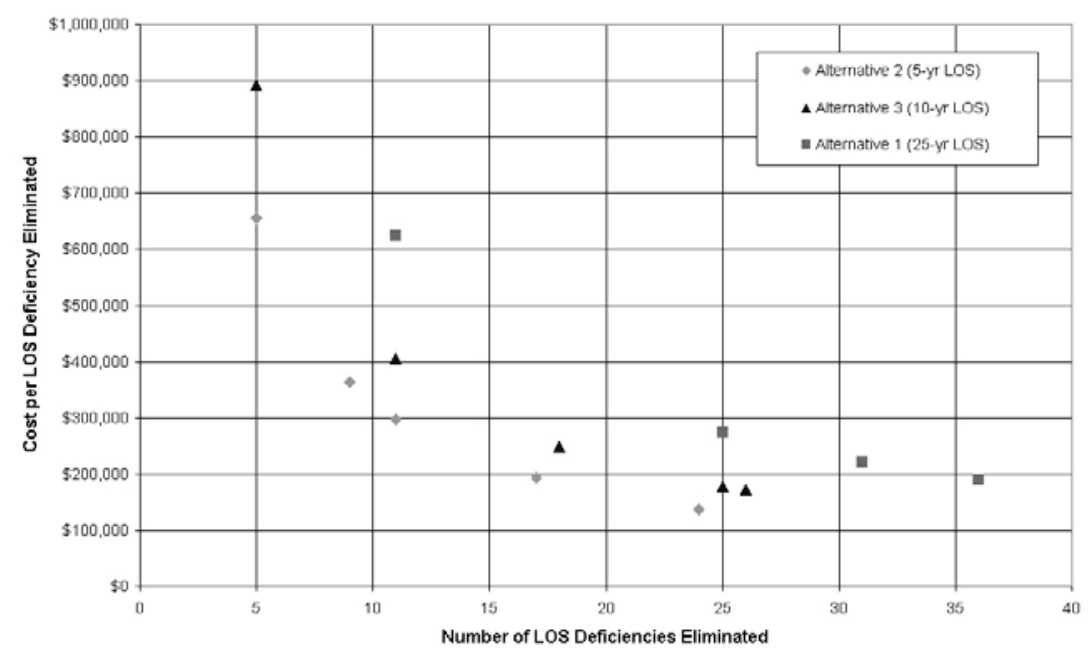

Figure 1.5 Number of LOS deficiencies eliminated by each alternative vs the cost per LOS deficiency eliminated (roads).

- production of comprehensive intercommunity storm drainage system mapping using Geographic Information Systems (GIS) to consolidate data for future use,

- development of tools to assist District service area communities in complying with EPA National Pollutant Discharge Elimination System (NPDES) Phase II Storm Water Regulations, and

- collection and management of data needed to support a regional storm water management program.

The RIDE study includes 27 urban watersheds covering a total area of 414 square miles $\left(1072 \mathrm{~km}^{2}\right)$ as shown in Figure 1.7. The study area encompasses all or part of 60 communities that are located either within the District's service area or in adjoining watersheds. The stormwater management system was modeled and calibrated using EPA SWMM and includes over 763 miles $(1228 \mathrm{~km})$ of open channels, culverted streams, and storm sewer pipes. This 
chapter describes improvements developed for one of the watersheds, Wood Creek, which covers 3.5 square miles $(9.1$ sq. km) and includes 6.8 miles (11 $\mathrm{km}$ ) of open channels, culverted streams, and pipes. Improvements were also developed to address erosion problems but are not described in this chapter.

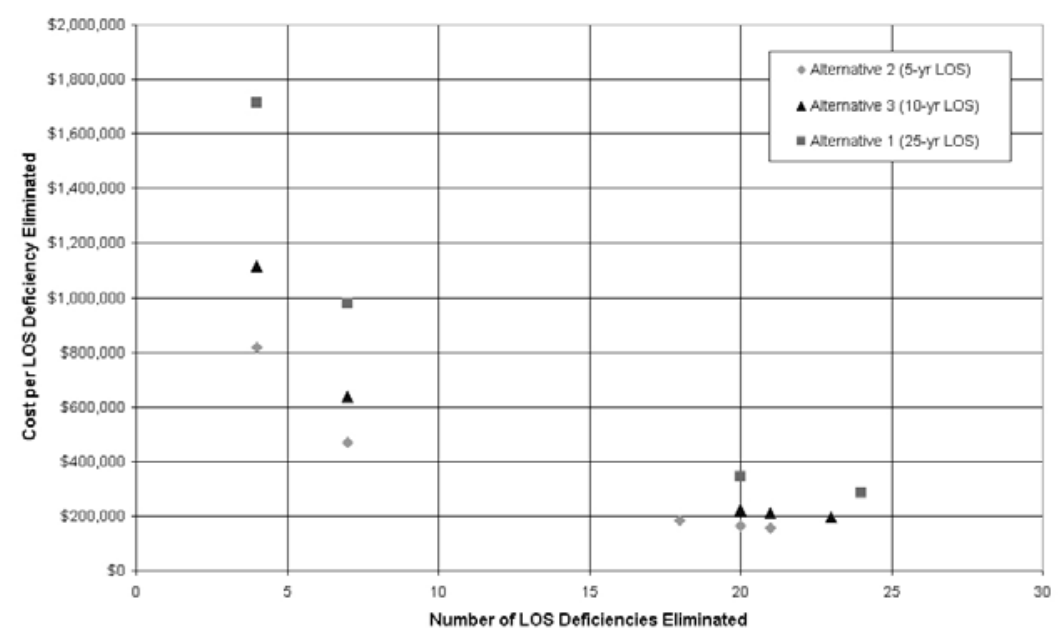

Figure 1.6 Number of LOS deficiencies eliminated by each alternative vs the cost per LOS deficiency eliminated (buildings).

\section{Summary of Alternatives}

For this study, four alternatives were developed that achieved a common level of flood protection, as described by the following design LOS criteria:

- no commercial or residential building flooding for the $25 \mathrm{y} / 24 \mathrm{~h}$ design storm event,

- maximum peak flood stage $1 \mathrm{ft}(300 \mathrm{~mm})$ below the road crown elevation for the $25 \mathrm{y} / 24 \mathrm{~h}$ design storm event for arterial traffic routes, and

- maximum peak flood stage below the road crown elevation for the $10 \mathrm{y} / 24 \mathrm{~h}$ design storm event for local traffic routes.

For each alternative, a set of structural improvement types was developed to meet these LOS criteria in six distinct flooding problem areas, described as follows:

- Alternative A represented conveyance improvements including $12,960 \mathrm{ft}(3950 \mathrm{~m})$ of storm sewer, $650 \mathrm{ft}(200 \mathrm{~m})$ of culverts, and $1,940 \mathrm{ft}(590 \mathrm{~m})$ of open channel. 
- Alternative B represented detention improvements including 68.0 million gallons $\left(257000 \mathrm{~m}^{3}\right)$ of storage in 8 detention basins.

- Alternative $\mathrm{C}$ represented floodplain management improvements including $211,300 \mathrm{ft}^{2}\left(19630 \mathrm{~m}^{2}\right)$ of raised roadway surface area, $980 \mathrm{ft}(300 \mathrm{~m})$ of concrete floodwall, 200 $\mathrm{ft}(60 \mathrm{~m})$ of earthen flood berm, buyout of 21 commercial and residential properties.

- As each set of Alternatives A-C were optimized, some improvement options were noted to perform hydraulically better than others, in terms of achieving greater flood protection benefit for relatively small changes in improvement size or quantity. Based on this information, a combination of improvements was formulated which generally used the most effective solution for each flooding problem area. Alternative D represented a combination of improvements including $9,260 \mathrm{ft}$ $(2820 \mathrm{~m})$ of storm sewer improvements, $43.3 \mathrm{MG}\left(164000 \mathrm{~m}^{3}\right)$ of detention storage, and $4,800 \mathrm{ft}^{2}\left(450 \mathrm{~m}^{2}\right)$ of raised roadway surface area.

\section{Alternatives Evaluation}

Each of the alternatives developed for the Wood Creek watershed were evaluated using six specific weighted evaluation criteria, including:

- Capital and Operational Costs (30\% weighting). Design and construction costs, as well as operation and maintenance costs for new facilities, were determined for each alternative. Annual operation and maintenance costs were estimated over a $50 \mathrm{y}$ planning horizon and converted to total present worth. The total project costs were normalized so that the most expensive alternative received a score of 0 . The remaining alternatives received scores between 0 and 10 based upon the ratio of their cost compared to the highest cost alternative.

- Improvement Effectiveness (30\% weighting). The effectiveness score of each proposed alternative was quantified using the flooding problem ranking system shown in Table 1.2. Each alternative that met the design LOS criteria for all problem areas within the watershed received the maximum effectiveness points. Some alternatives, particularly floodplain management options, did not resolve certain flooding problems and in such cases were not credited with effectiveness points for the unresolved problems. The effectiveness scores were normalized 
so that the most effective alternative received a score of 10 . The remaining alternatives received scores between 0 and 10 based upon the ratio of their effectiveness compared to the most effective alternative.

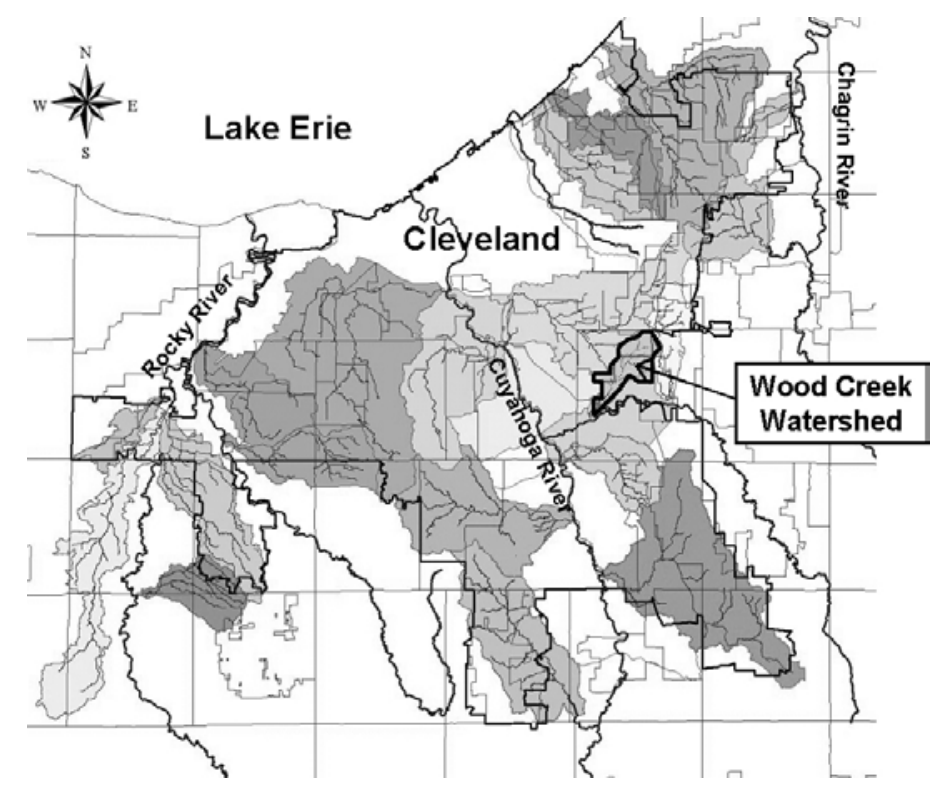

Figure 1.7 Case Study 2 project location (Cleveland Ohio).

- Compatibility with Community Interests (10\% weighting). Starting with a base score of 5 , up to 5 points were added depending on the degree to which the alternative provided multi-use opportunities and/or supported local or regional land use planning objectives. In addition, up to 5 points were subtracted depending on the degree to which the alternative involved relocation of residents and/or presented significant safety or aesthetic concerns. In this way, scores ranged from 0 to 10.

- Consistency with Regulatory Requirements (10\% weighting). Starting with a base score of 5 , up to 5 points were added if alternatives were consistent with NPDES Phase II, TMDL, FEMA floodplain management requirements, and state dam safety permitting requirements. Up to 5 points were subtracted if alternatives were unfavorable or inconsistent with regulatory requirements. Alternatives that were neutral did not receive additional points. In this way, scores ranged from 0 to 10 . 
- Environmental Benefits (10\% weighting). Starting with a base score of 0 , up to 10 points were added depending on the degree to which improvements incorporated water quality enhancement or stream restoration features.

- Implementation Issues (10\% weighting). Starting with a base score of 10 , up to 10 points were subtracted depending on the degree to which the construction of improvements would disrupt the public and operation of businesses, require easement or land acquisition, and maintenance requirements.

After assigning the appropriate score for each criteria, the score was multiplied by the corresponding weighting factor, giving an overall evaluation score for the alternative between 1 and 10. For the Wood Creek watershed, the overall scores were:

- Alternative A (Conveyance Improvements): 6.0,

- Alternative B (Detention Improvements): 6.7,

- Alternative C (Floodplain Management Improvements): 3.3, and

- Alternative D (Combination Improvements): 6.8.

Alternative evaluation results for the Wood Creek watershed did not establish a clear favorite, but they did rule out the floodplain management improvements from further consideration in subsequent project phases.

Based on this method of alternatives evaluation, the RIDE study recommended capital improvement projects for both flood and erosion control, including projected program costs and suggested implementation activities in each of the 27 watersheds.

\subsection{Conclusions}

Capital improvement projects are vital to the quality of living within a community and form the backbone for future growth and development. It is expected that competing demands for limited public funds will continue. As a result, engineers will need to be more diligent in developing cost-effective improvement projects to meet an increasing variety of needs and user demands for stormwater management systems.

The purpose of this chapter was to highlight issues and approaches in the development and evaluation of stormwater improvement alternatives. In addition, methods for quantifying and prioritizing stormwater problems were discussed as well as important cost, benefit, and improvement optimization considerations. Two case studies were presented that highlighted different variations on the approach for evaluating alternatives for proposed capital improvement projects. 


\section{References}

CDM Inc. (2001). City of Clearwater (Florida), Myrtle Avenue Stormwater Improvement Project, Phase 1 Final Report.

CDM Inc., MWH Inc., and WRCE Inc. (2003). Northeast Ohio Regional Sewer District, Regional Intercommunity Drainage Evaluation, Lower Tinkers Creek Drainage Area Draft Report.

Cunningham, B.A. and M.F. Schmidt (1993). Improving Upon Conventional Stormwater Detention Ordinances. Proceedings of the ASCE/EPA Water Quantity and Quality Modeling Conference.

French and Associates Ltd. (1998). Managing Floodplain Development through the National Flood Insurance Program. Home study course IS-9 prepared for the US Federal Emergency Management Agency, available at http://www.floods.org/Certification/is9.asp.

Gregory, M., M.F. Schmidt and J. Aldrich. 2003. "Level of Service Evaluations For Stormwater Assessments." Journal of Water Management Modeling R215-04. doi: 10.14796/JWMM.R215-04.

Huber, W.C. and R.E. Dickinson (1988). SWMM Version 4 User's Manual. US Environmental Protection Agency.

US Environmental Protection Agency (2003). Clean Watersheds Needs Survey 2000, Report to Congress. EPA-832-R-03-001. 
